\title{
Role of gustation in sodium appetite*
}

\author{
LEO V. DiCARA and LINDA M. WILSON \\ Mental Health Research Institute, University of Michigan, Ann Arbor, Michigan 48104
}

\begin{abstract}
Previous studies indicated that gustatory signals are critical for regulation of sodium intake. The present study was concerned with the relative effects of sodium repletion via ingestion and via gastric intubation upon the satiation of sodium appetite in rats subjected to sodium depletion for the first time in their lives. The results showed that, in comparison to glucose or sham intubation, sodium intubation has no short-term satiating effect, whereas prior ingestion of sodium results in complete satiation of sodium appetite.
\end{abstract}

An important role of taste in the identification of sodium salts (Handal, 1965; Nachman, 1962) in the maintenance of sodium intake (Mook, 1969; Smith, 1972 ) and in the satiation of sodium appetite (Nachman \& Valentino, 1966) is now well established. Taste appears to be much more critical for regulation of sodium intake than for food or water intake, which can be controlled without gustatory input (Epstein, 1967). There is, in fact, evidence that taste may be the sole mechanism by which the appetite for sodium can be satiated-at least within a few hours after repletion. Nachman and Valentino (1966), in a very important study, found that stomach loading of a salt solution was not more effective in satiating sodium appetite than was loading of an equal volume of water or of glucose solutions, even though the loading returned blood sodium levels to normal. On the other hand, when an equal volume of salt solution was ingested, the animals manifested an appropriate reduction of sodium appetite in a subsequent test.

In recent unpublished investigations aimed at elucidating the nature of receptor mechanisms for sodium intake, we unexpectedly found suggestive evidence of a small but significant satiating effect of sodium administered by gastric intubation in experimentally naive rats presumably experiencing sodium deficiency for the first time. Nachman and Valentino (1966) used adrenalectomized rats which had been accustomed to repeated sodium deprivation and regular brief drinking periods, so that long-standing ingestion habits may have obscured a satiating effect of the gastric sodium load. The present study was done to determine whether there is an extragustatory short-latency satiating effect of extraoral sodium replenishment in rats experiencing sodium deficiency and repletion for the first time.

\section{METHOD}

Twenty-four adult male albino rats weighing between 350 and $450 \mathrm{~g}$ and maintained in individual home cages were used. The

*This investigation was supported by Grant $\mathrm{MH} 21403$ awarded to the senior author. rats were raised from weaning in the laboratory. They were given water and chow containing $0.7 \% \mathrm{NaCl}$ (over 10 times the minimal requirement) ad lib to insure that they would not experience a deficiency of sodium prior to the experiment. They were adapted to a feeding period of $1 \mathrm{~h}$ per day with deprivation of all food and fluid during the remaining $23 \mathrm{~h}$. During the daily feeding period, they were given a $0.5 \mathrm{M} \mathrm{NaCl}$ solution, distilled water, and condensed milk in graduated dispensers in their home cages. After 2 weeks of adaptation to the feeding regimen, all rats were injected subcutaneously with $2.5 \mathrm{ml}$ of $1.5 \%$ Formalin immediately following the feeding period to induce sodium deficiency (Stricker \& Wolf, 1969). The rats were divided into four groups of six rats matched for spontaneous sodium intake during the adaptation period. Thirty minutes before the feeding period of the next day, the four groups were treated as follows: a salt ingestion group was given $8.0 \mathrm{ml}$ of $0.5 \mathrm{M} \mathrm{NaCl}$ solution to drink, a salt intubation group was intubated with $8.0 \mathrm{ml}$ of $0.5 \mathrm{M}$ $\mathrm{NaCl}$, a glucose intubation group was intubated with $8.0 \mathrm{ml}$ of $1.0 \mathrm{M}$ glucose solution, and a sham intubation group received the stomach catheter but nothing was intubated. Thirty minutes later, the rats were given $0.5 \mathrm{M} \mathrm{NaCl}$ solution and water to drink for $1 \mathrm{~h}$. No milk was given during the feeding period of the test day. The experiment was terminated following the $1-h$ feeding period.

\section{RESULTS}

Table 1 shows saline and water intake of individual rats of the four groups during the 1-h feeding period of the test day. The rats of the salt ingestion group all consumed the entire $8 \mathrm{ml}$ of saline during the first $10-20 \mathrm{~min}$ of the $30-\mathrm{min}$ period preceding the $1-\mathrm{h}$ feeding period. The rats of this group ingested an average of less than $1 \mathrm{ml}$ of saline during the feeding period, and that was significantly less than the average $(8-10 \mathrm{ml})$ of the other three groups $(p<.0005)$. The salt intubation group did not ingest significantly less saline than either the glucose intubation group or the sham intubation group. The water intake of all groups was relatively high $(20-30 \mathrm{ml})$ as a result of the hypovolemic effects of the Formalin treatment (Stricker \& Wolf, 1969). The water intake of the glucose intubated group was somewhat less than that of the other three groups $(p<.005)$, and we can offer no explanation of this effect at the present time. 
Table 1

$0.5 \mathrm{M}$ Saline and Water Intake of Individual Rats of the Four Groups During 1-H Feeding Period

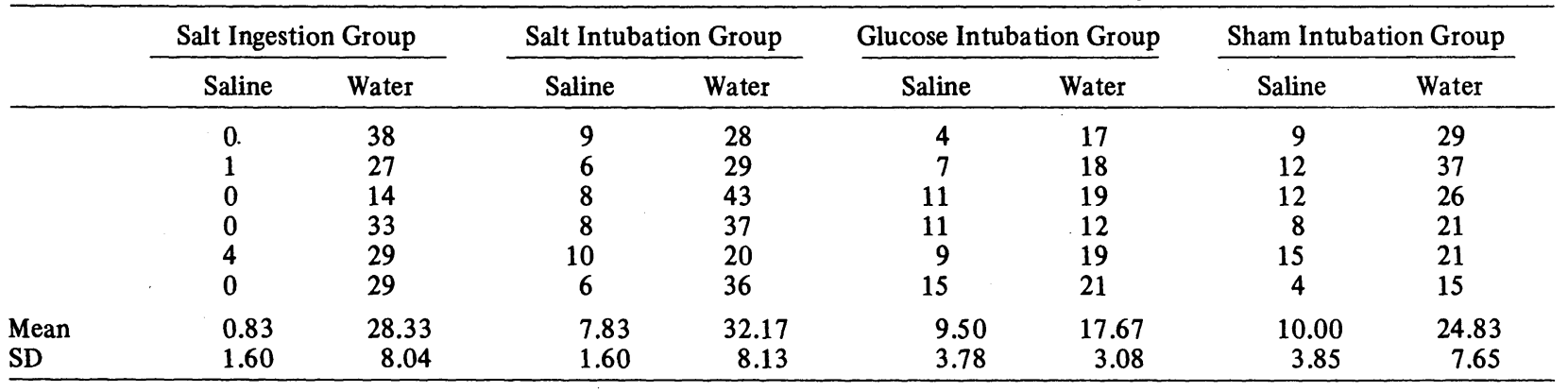

\section{DISCUSSION}

The results show very clearly that rats experiencing sodium deprivation and repletion for the first time do not respond to repletion of sodium via gastric intubation by a diminution of subsequent sodium intake. However, if the sodium reaches the stomach by normal oral ingestion, complete satiation occurs. It is also important to note that the period between intubation and completion of the testing was ample time for the sodium to be absorbed from the gastrointestinal tract (Nachman \& Valentino, 1966). Thus, there appears to be no extraoral (presumably extragustatory) mechanism for short-latency satiation of sodium appetite.

The behavioral observations that gustation is critical for the regulation of sodium intake reported here, as well as that reported by other workers (Handal, 1965; Mook, 1969; Nachman \& Valentino, 1966; Smith, 1972), correspond with both endocrinological findings on the control of aldosterone secretion and neurological data on the gustatory system. Denton's group has made the fascinating finding that oral intake of sodium is much more effective than parenteral repletion in shutting off aldosterone secretion in the sheep (Blair-West et al, 1972). Research conducted in this laboratory shows that lesions of the gustatory nucleus of the thalamus severely impair sodium intake regulation in the rat (DiCara \& Wolf, in press). Since destruction of the cortical gustatory area does not impair sodium intake (Wolf, DiCara, \& Braun, 1970), it would seem that the critical integration process takes place in the brainstem. A potential circuit for such integration has recently been demonstrated in the reticular formation (Wolf, 1971). This circuit interconnects the sensory regions of the thalamus and lower brainstem with the motivational and visceral centers of the hypothalamus. Thus, rapid cessation of both behavioral and endocrine responses to sodium deficiency can be mediated by gustatory input signaling sodium ingestion, conveyed through the reticular formation to the hypothalamus.

\section{REFERENCES}

Blair-West, J. R., Coghlan, J. P., Denton, D. A., Funder, J. W., \& Scoggins, B. A. The role of the renin-angiotensin system in control of aldosterone secretion. In T. A. Assaykeen (Ed.) Control of renin secretion. New York: Plenum, 1972. Pp. 167-187.

DiCara, L. V., \& Wolf, G. Decrements in sodium appetite after lesions of gustatory thalamus: Replication and extension. Behavioral Biology, in press.

Epstein, A. M. Feeding without oropharynoeal sensations. In $\mathbf{M}$ $R$. Kare and $O$. Maller (Eds.), The chemical senses and nutrition. Baltimore: Johns Hopkins Press, 1967. Pp. 263-280.

Handal, P. J. Immediate acceptance of sodium salts by sodium-deficient rats. Psychonomic Science, 1965, 3 315-316.

Mook, D. G. Some determinants of preference and aversion in the rat. Annals of the New York Academy of Science, 1969 157, 1158-1175.

Nachman, $M$. Taste preferences for sodium salts by adrenalectomized rats. Journal of Comparative \& Physiological Psychology, 1962, 55, 1124-1129.

Nachman, M., \& Valentino, D. A. The role of taste and postingestional factors in the satiation of sodium appetite in rats. Journal of Comparative \& Physiological Psychology, $1966,62,280-283$.

Smith, M. Evidence for a learning component of sodium hunger in rats. Journal of Comparative \& Physiological Psychology, $1972,78,242-247$.

Stricker, E. M., \& Wolf, G. Behavioral control of intravascular fluid volume: Thirst and sodium appetite. Annals of the New York A cademy of Science, 1969, 157, 553-568.

Wolf, G. A third ascending hypothalamopetal pathway. Experimental Neurology, 1971, 33, 69-77.

Wolf, G., DiCara, L. V., \& Braun, J. J. Sodium appetite in rats after neocortical ablation. Physiology \& Behavior, 1970, 5, 1265-1269.

(Received for publication October 18, 1973; accepted October 25, 1973.) 